Occurring, as it did, at a time when thousands were wending their way to chur:h, it must have been very generally observed. Harrow, October 26 A. W. B. J.

\section{Singing Mice}

WHEN at school a friend and I used to keep tame mice, and amongst our large stock was one of the so-called singing mice. The mouse in question was not one we bred ourselves, but was bought from a London dealer, so we had no opportunities of knowing whether it had ever been kept near a singing bird or not; but it was not at all averse to perfurming in broad daylight, arid. would chirp whilst a knot of boys were standing round it as freely as when the cuphoard was closed.

As M. Brierre describes it (vol. xvi. p. $55^{8}$ ), the mouse used to sit with its snout more or less elevated, but not at all to an uncomfortable height, and i's throat used to throb like that of a bird whilst :inging, the fur of the one being ruffled like the featbers of the other; and the song was something between that of a wren and that of a shrew mouse, and rather pleasing than otherwise.

At first we were inclined to attribute the nuise to disease of the lungs or throat, but were unable to hold that opinion long, as there never seemed to be any pain or gasping connected with it, but the noise was always produced at periods of greatest rest, and chiefly when the mouse came out of its sleeping place to wash its face and paws, at which times it generally chirped at intervals. It never had the power of imparting the art to ottiers, nor did any of its numerous progeny inherit its powers. Neither was it all short lived, but rather the contrary, and its death was caused by an accident. We were unable to consider the power of emitting the sounds at all the result of weakness or disease.

HENRY H. SLATER

\section{Scund-Producing Arthropods}

I HAVE read with much interest the brief abstract given in NATURE (vol. xvi. p. 567) of Mr. Wood Mason's amnouncement to the Eritomological Society of the discovery of stridulating orgens in association with scorpions; reference being made at the same time to his recognition of similar sound-producing structures among other Althropoda, including certain Crustacea. In this latter case no mention is made of the particular types with which these sound-organ; have been observed, and I therefore hazard the relation of an instance that has recently fallen under my own observation with the chance of its proving a newlyrecorded example.

The crustactan in question, which I have ascertained to possess sound-producing properties to an eminent degree, is a species of Sipheromia, belonging to the Isopodous order of the class. I have rot as yet ascertained the exact method in which sound is produced nor whether the animai has organs specially adapted for the purpose ; on numerous occasions, however, my attention has becul attracted to the grass jar of which, with the exception of microscopic Copepods and Protozoa, a single specimen of the species is the sole animal occupant, by a little sharp tapping sound produced three or four times consecutively with intervals of ahout one second's duration, and which I can almost exactly imitate by gently striking the side of the jar with the pointed $\epsilon$ nd of a pipette. On being approached the little creature always endeavours to elude notice by passing to the opposite side of the stalk of seawee3, upon which it usua!ly reposes in the same way that a squirrel dodges round the bianch of a tree, and on no occasion so far have I been able to catch the little fellow fagrante delicto, or in the act of producing the sound which it most undoubtedly emits. The character and intensity of the sound produced associated with the small size of the animal, scarcely one quarter of an inch in length, induces me to believe that it is caused by the sudden flexion and extension of the creature's body. A more prolonged observation will no doubt clear up this point, but Mr. Wood Mason may possibly be in a position to throw further light upon the subject by means of the evidence he has collected in reference to other crustacean types.

Among the higher Decapodous crustacean order one species, Alpheus ruber, frequently collected by me in Guernsey, produces a snapping noise beneath the water by the sudden extension of the terminal joint of its larger claw that can be heard at a considerable distance, and that at once betrays its lurking place to a practised ear. The large sea crayfish (Falinurnes quadricornis) again, oiten emits when handled what may be filly described as a shrill squeaking sound by the rubbing together of the spinous abdominal segments. It would seem indeed that a closer study of the life habits of the aquatic Arthropoda is likely to reveal among its membars as infinite a variety of soun'-preducers as has hitherto been determined to exist among the r more familiar terrestrial congeners.

St. Heliers, Jersey, October 27

\section{Insects and Flowers}

IN reference to the question whether insects are most attracted to flowers by scent or colour, may I mention that while staying at the hotel at Cettinge lately I was amused by the behaviour of some humming-bird sphinx moths. My roam was roughly stencilled with a "spotty" pattern of prrplish brown on the duil white plaster. Every morning the:e moths, with their probosces extended, used to attack the dabs of colour, hovering hefore the $x$, just as though they were real flowers, but starting back with apparent amazement on finding that they were not. This seems the more remarkable because the wonderfully abundant aro. matic herbs of that region, which must have supplied their usual food, have all, so far as I know, very inconspicuous flowers.

Notting Hill, October 27

A. J. H.

\section{FRANCIS VON ROSTHORN}

FRANCIS VON ROSTHORN; who died June 17 , 1877, was the son of Matthew Rosthorn, of Lancashire, who went to Vienna in 1765 , at the invitation of the Empress Maria Theresa, to establish the manufacture of metal buttons. He constructed the first rolling-mills in Austria; one at Vienna, another (in 1792) at Fahrafeld, in Lower Austrix. Nathew von Rosthorn was ennobled by the Emperor Joseph II. in 1790, and died at Vienna January 3, I805, leaving five sons. The youngest of these, born April 18, 1795, at Vienna, is the subject of this notice. These five brothers joined in creating extensive metallurgic establishments; the first (I817) at Oed; and another (1823) in Carinthia, for smelting zinc (then high in price) out of the Raibl and Bleyberg ores, by means of brown coal. Having purchased (1826) the state demesne of Wolfsberg, in Carinthia, with extensive metallurgical works, they constructed there a large rolling-mill, together with a puddling furnace. Francis von Rosthorn, having prepared himself for his practical career by attending the Mining Academy of Schemnitz, in Hungary (1814 to 1818 ), soon became acquainted with several eminent geologists, and obtained the patronage of the late Archduke John. He made several scientific tours in Carinthia, Carniolia, Styria, Salzburg, and the Hungarian border;: in 1827 with Prof. Keferstein, in 1828 with Archiduke John, in 1829 with Escher and Schröter, and in 1832 with Dr. Boué. His annual visits to Archduke John at Gastein (1829 to 1836) were always connected with Alpine exploration. His later travels (I 842 to 1847 ) were chiefly southward. In 1832 he communicated the results thus obtained to the Meeting of German Naiuralists at Vienna; and in 1836 to the meeting at Freiburg. In 1848 he was elected into the Legislative Assembly ("Landtag") of Carinthia; and from 1852 to 1870 held the office of President of the Commercial and Industrial Board of that province. Francis von Rosthorn's constitution was exceptionally robust, so that up to his seventy-sixth year he was able to undertake arduous Alpine ascents. His conversation with persons of any social station was unaffectedly amiable; but he could be sarcastic when he met with affectation or baseless pretensions.

\section{SPECTRUM OF AURORA AUSTRALIS}

$A S$ I believe no account of spectroscopic observations of the Aurora Australis have as yet been published, I venture to send this description of two auroræ observed during the stay of H.M.S. Chalienger in high southern I Obituary Notice by Prof, E. Suess(' Report of the Imperial Geological Institute, Vienna," August .31, 1877) 
latitudes. The opportunities of observing were not frequent, either from the rarity of the phenomena (which is very possible) or because the dense mass of cloud which is the prevailing feature of those regions prevented their being seen except when exceptionally bright.

Altogether four appearances were noted. The first was 1.30 on the morning of February 9,1874 , in lat. $57^{\circ} \mathrm{S}$. and long. $75^{\circ} \mathrm{E}$., bar. $29^{\circ} \mathrm{O}$ in., ther. $35^{\circ}$. There were brilliant streaks to the westward ; no spectroscopic observations were taken. The second was on February 21 at 9.30 P.M., lat. $64^{\circ}$ S., long. $89^{\circ}$ E., bar. 288 , ther. $31^{\circ}$; one bright white curved streamer extended from Jupiter, which appeared to be near the focus, through Orion and about as far beyond. Under this was what appeared to be a black cloud, but the stars were visible through it. Real cumulus clouds hid great part of the remainder, but there were two vertical flashing rays that moved slowly to the right (west), generally the aurora was still and bright.

On examining the streamer with the spectroscope I found the usual three prominent lines, namely, one yellow-green, one green, the third blue or purple. I looked for the red line but could not find it.

The third aurora was seen on March 3, lat. $53^{\circ} 30^{\prime}$ S., long. $109^{\circ}$ E., bar. $29^{\circ} x$, ther. $36^{\circ}$, after some days wet and stormy weather. Soon after 8 p.M. the sky began to clear and the moon shone out. Noticing the light to the southward to be particularly bright I applied the spectroscope and found the distinguishing auroral line. About midnight I was called as there were very brilliant auroral clouds. The sky was almost clear, but sonth were two or three brilliant light clouds, colour very white yellow, shape cumulus stratus; from about west to near south extended a long feathery light of the same colour, parallel with the horizon, and between south and west there appeared occasionally brilliant small clouds, the upper edges seemed hairy, and gave one the idea of a bright light behind a cloud. The forms changed, but I did not notice any particular order, perhaps because my attention was particularly directed to examining the light with the spectroscope, and the great cold, for my fingers seemed almost frozen, and the motion of the ship made my task rather difficult. I could trace four lines, three bright, and one rather faint, and by reference to the moon, which was shining brightly, roughly determined their places. They must have been exceedingly bright to show so plainly in full moon. The spectroscope used was one of Grubb's single prism with long collimator. A needle point in the eye-piece marked the position of the lines, and a corresponding needle point carried on a frame with the point in the eye-piece and moved by a coarse thread screw, scratched the lines on a plate of blackened glass. I took two plates; - on the first I scratched the auroral lines and the telluric lines visible in the moonlight; on the second I scratched the auroral lines, the telluric lines shown by the moon, and the lines given by carbon in the flame of a spirit lamp; the next morning I verified the lines in sunlight. The lines marked $\mathrm{A}$ are those shown

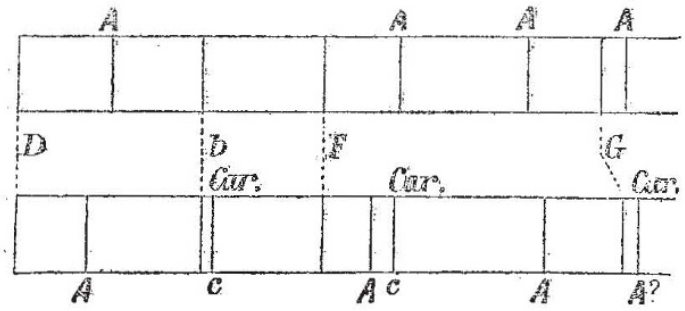

by the aurora, those marked $D, b, F$, and $G$ are the telluric lines, and those marked car. were given by the carbon in the spirit lamp.

The spectrum has been magnified five times from the plates. I cannot account for the different position of the auroral lines in the two plates, as the prism was not moved during the observations that I am aware of.

The fourth aurora was a slight one seen to the southward on March 6 at 8 P.M. It would be worth investigating whether the low barometer has anything to do with the absence of red in the spectrum, the normal state of the barometer is an inch lower in those regions than in more temperate latitudes.

I may as well add that on February 9 the aurora was preceded by a watery sunset, and the day broke aíterwards with high cirrus clouds and clear horizon. On February $2 \mathrm{r}$ the aurora preceded a fine morning, cumulus stratus clouds. On March 3 there was a brilliant sunset followed by a fine morning; and on March 6, after the slight appearance of aurora, the clouds changed to high cirrus.

\section{J. P. MACLEAR}

\section{ABSOLUTE PITCH}

$A \mathrm{~T}$ the present time the question of absolute pitch is A attracting attention in consequence of the discrepancy between König's scale and the numbers determined by Appunn's tonometer. This instrument is founded upon the same idea as Scheibler's fork tonometer, and consists of a s.ries of sixty-five harmonium reeds, bridging over an entire octave, and so tuned that each reed gives with its immediate neighbours four beats per second. The application to determine absolute pitch, however, does not require precision of tuning, all that is necessaiy being to count with sufficient accuracy the number of beats per second between each pair of consecutive reeds. The sum of all these numbers gives the difference of frequencies of vibration between the first reed and its octave, which is, of course, the same as the frequency of the first reed itself.

The whole question of musical pitch has recently been discussed with great care by Mr. Ellis, in a paper read before the Society of Arts (May 23, 1877). He finds by original observation with Appunn's instrument $25^{\circ} .4$ as the actual frequency of a König's 256 fork, and Prof. Preyer, of Jena, has arrived at a similar result (258.2). On the other hand, Prof. Mayer in America, and Prof. Macleod in this country, using other methods, have obtained numbers not differing materially from König's. The discrepancy is so considerable that it cannot well be attributed to casual errors of experiment; it seems rather to point to some defect in principle in the method employed. Now it appears to me that there is such a theoretical defect in the reed tonometer, arising from a sensible mutual action of the reeds. The use of the instrument to determine absolute frequencies assumes that the pitch of each reed is the same, whether it be sounding with the reed above, or with the reed below; and the results arrived at would pe vitiated by any mutual influence. In consequence of the ill-understood operation of the wind, it is difficult to predict the character of the mutual influence with certainty; but ("Theory of Sound," \$§ II2-II5) there is reason to think that the sounds would repel one another, so that the frequency of the beats heard when both reeds are sounding, exceeds the difference of the frequencies of the reeds when sounding singly. However this may be, in view of the proximity of consecutive reeds and of the near approach to unison? the assumption of complete independence could only be justified by actual observation, and this would be a matter of some delicacy. If the mutual influence be uniform over the octave it would require a difference of one beat per minute only to reconcile König's and Appunn's numbers.

As to the amount of the influence I am not in a position to speak with confidence, but I may mention an obser-

I. It must not be forgotten that the vibration of the tongue involves a transference of the centre of inertia, so that there is a direct tendency to set the sounding-board into motion. 